\title{
Pharmacodynamics of Propranolol in Renal Failure
}

\author{
F. D. THOMPSON, \\ A. M. JOEKES, \\ D. M. FOULKES
}

\section{Summary}

The pharmacodynamics of propranolol were studied in patients with renal functional impairment. "C-labelled propranolol was given either intravenously or by mouth and the disappearance rates of propranolol, 4-hydroxypropranolol, and total radioactive metabolites measured. The renal clearance of total radioactive compounds is directly related to renal function. The half-life of total radioactivity is greatly lengthened in the presence of severe renal failure while the half-lives of the pharmacologically active propranolol and 4-hydroxymetabolite are slightly reduced. There is a suggestion that the absorption of propranolol is delayed in renal failure. No known pharmacological action or side effects from the other metabolic products of propranolol have been recognized. There is still too little well-documented evidence concerning the beta-blocking activity of the unidentified major metabolites of propranolol to suggest any alteration in the dosage regimen used in renal failure.

\section{Introduction}

Many of the drugs currently used in the control of hypertension have side effects which often limit their clinical use. Postural hypotension, sexual impairment, failure of memory, muscular weakness, and depression are among the common limiting factors. With the advent of beta-adrenergic blockade a new approach to the management of hypertension became available and propranolol has been advocated as one of the drugs of choice in the treatment of hypertension (Prichard and Gillam, 1969; Zacharias and Cowen, 1970). The pharmacodynamics and beta-blocking activity of this compound and its major metabolites in normal subjects have been described by Paterson et al. (1970).

In humans propranolol is metabolized to 4-hydroxypropranolol and naphthoxylactic acid as well as unidentified metabolites (Fig. 1). Recent studies have shown that the unidentified

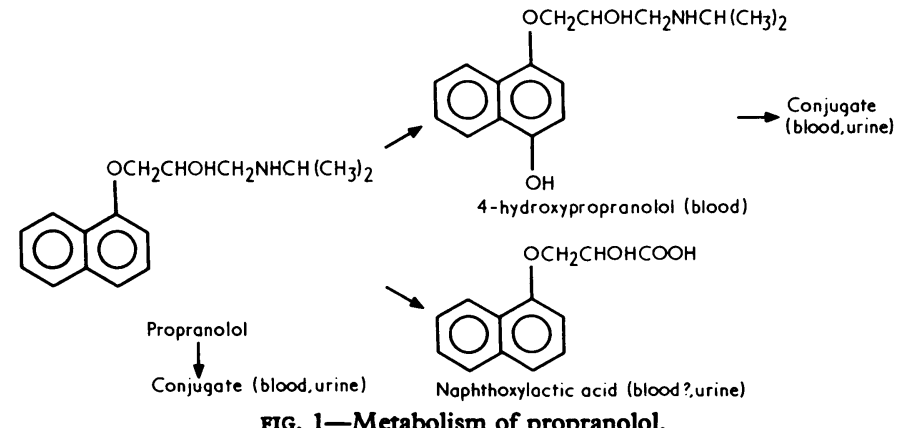

FIG. 1-Metabolism of propranolol.

Institute of Urology, St. Peter's Group of Hospitals, London W.C.2 F. D. THOMPSON, M.B., B.CHIR., M.R.C.P., Research Registrar A. M. JOEKES, B.M., B.CH., F.R.C.P., Nephrologist and Senior Lecturer

Research Department, I.C.I. Pharmaceuticals Division, Macclesfield, Cheshire

D. M. FOULKES, PH.D. metabolite in blood is an acid labile conjugate of a mixture of propranolol and 4-hydroxypropranolol which is identical with the major metabolite found in urine (D. M. Foulkes and J. Siddall, unpublished observation). Only trace amounts of propranolol and 4-hydroxypropranolol are found in urine. The main urinary components are naphthoxylactic acid and the uncharacterized conjugates. The handling of propranolol in patients with renal failure has not been previously examined. The aim of the present study was to establish the pharmacodynamics of propranolol in patients with widely varying degrees of renal functional impairment.

\section{Patients and Methods}

Some details of the 14 patients studied are given in Table I. On nine occasions a single intravenous dose of ${ }^{14} \mathrm{C}$-labelled propranolol was given. On seven occasions a single oral dose of ${ }^{14} \mathrm{C}$-labelled propranolol was administered. In Case 3 both an

TABLB I-Blood Pressure and Creatinine Clearance in the 14 Cases

\begin{tabular}{|c|c|c|c|c|c|}
\hline \multicolumn{2}{|c|}{ Case No. } & Age & Sex & $\begin{array}{l}\text { Blood Pressure } \\
\text { mm Hg Supine }\end{array}$ & $\begin{array}{c}\text { Creatinine Clearance } \\
(\mathrm{ml} / \mathrm{min})\end{array}$ \\
\hline \multicolumn{6}{|c|}{ Intravenous Administration } \\
\hline $\begin{array}{l}1 \\
2 \\
3 \\
4 \\
5 \\
6 \\
7 \\
8 \\
9\end{array}$ & $\begin{array}{l}\ldots \\
\because \\
\cdots \\
\cdots \\
\cdots \\
\cdots\end{array}$ & $\begin{array}{l}19 \\
44 \\
20 \\
58 \\
35 \\
49 \\
59 \\
56 \\
44\end{array}$ & $\begin{array}{l}\text { M. } \\
\text { M. } \\
\text { M. } \\
\text { M. } \\
\text { M. } \\
\text { M. } \\
\text { F. } \\
\text { M. } \\
\text { F. }\end{array}$ & $\begin{array}{l}130 / 80 \\
130 / 100 \\
190 / 100 \\
240 / 145 \\
150 / 105 \\
180 / 125 \\
180 / 80 \\
155 / 84 \\
170 / 115\end{array}$ & $\begin{array}{r}6.6 \\
7.4 \\
17.4 \\
24 \cdot 7 \\
28.0 \\
37.0 \\
40.0 \\
51.9 \\
62.0\end{array}$ \\
\hline \multicolumn{6}{|c|}{ Oral Administration } \\
\hline $\begin{array}{l}10 \\
11 \\
12 \\
3(\mathrm{a}) \\
3(\mathrm{~b}) * \\
13 \\
14\end{array}$ & $\begin{array}{l}\ldots \\
\ddot{0} \\
\cdots \\
\cdots\end{array}$ & $\begin{array}{l}60 \\
55 \\
60 \\
21 \\
21 \\
36 \\
43\end{array}$ & $\begin{array}{l}\text { M. } \\
\text { F. } \\
\text { M. } \\
\text { M. } \\
\text { M. } \\
\text { M. } \\
\text { F. }\end{array}$ & $\begin{array}{l}150 / 90 \\
150 / 80 \\
200 / 130 \\
160 / 80 \\
160 / 80 \\
160 / 200 \\
200 / 100\end{array}$ & $\begin{array}{r}2.0 \\
2 \cdot 6 \\
3 \cdot 6 \\
5 \cdot 0 \\
100 \cdot 0 \\
9 \cdot 0 \\
16.0\end{array}$ \\
\hline
\end{tabular}

*After renal transplant.

intravenous and two oral doses were given on separate occasions. This patient was studied over a period of a year, initially when he had advanced renal failure with a creatinine clearance of $17.4 \mathrm{ml} /$ minute, and on the second occasion when the renal clearance had fallen to $5 \mathrm{ml} /$ minute. Finally, he was studied after receiving a transplanted kidney which had good function of $100 \mathrm{ml} /$ minute.

The single intravenous dose was given as $1 \mathrm{mg}$ of ${ }^{14} \mathrm{C}$-propranolol hydrochloride and the oral dose was given as $20 \mathrm{mg}$ of ${ }^{14} \mathrm{C}$-propranolol hydrochloride. In both groups the radioactive dose was $20 \mu \mathrm{Ci}$ of ${ }^{14} \mathrm{C}$. Total urine and faeces were collected in plastic containers over the three days from the time of administration; in error no faecal marking was used. The radioactivity of the urine samples was measured by direct scintillation counting in an appropriate phosphor (Foulkes, 1970). The creatinine clearances were also measured. Faeces were homogenized in methanol and filtered. The methanol extracts were counted directly in a toluene based phosphor (Foulkes, 1970). Residual faecal material was dried and its radioactivity content measured after combustion (Kalberer and Rutschmann, 1961). Total radioactivity in oxalated whole blood was also determined by combustion. The propranolol and 4-hydroxypropranolol contents of the blood samples were measured as described by Hayes and Cooper (1971). 
TABLE II-Details of Observations

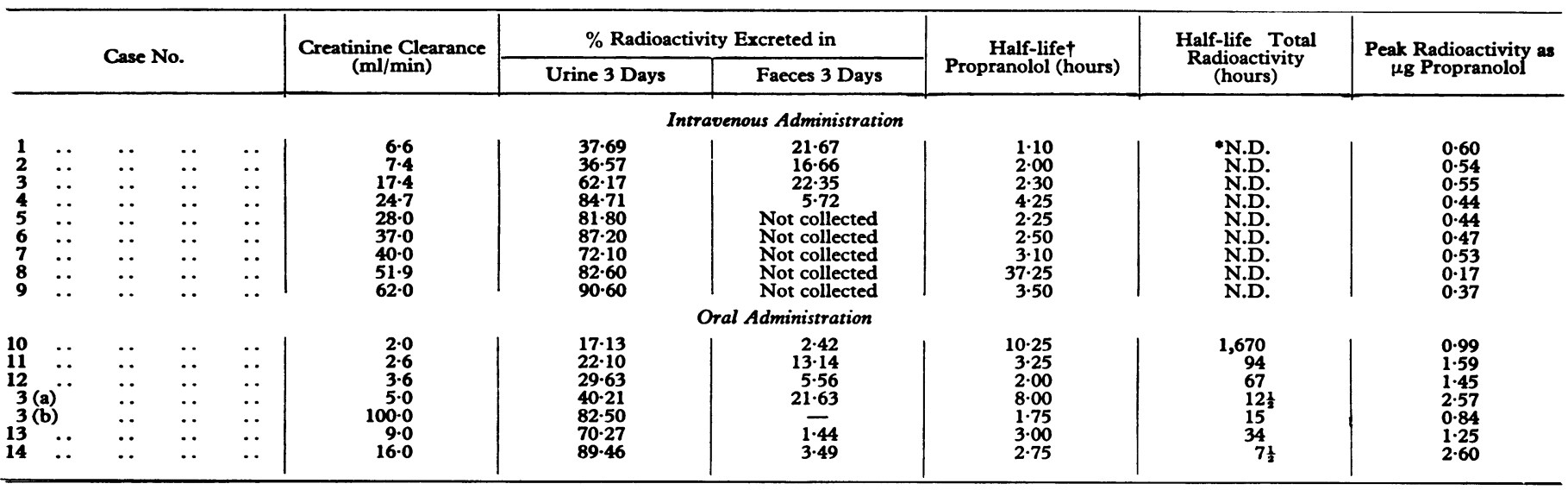

*N.D. In the observations involving intravenous administration blood sampling was terminated too soon to provide reliable half-life data. N.D. In the observations involving intravenous administration

\section{Results}

Details of observations in the two groups of patients are given in Table II. Faecal collections were made without markers and can represent only the minimum faecal excretion. The percentage of the total radioactive dose excreted in the urine in three days following administration is directly related to the renal function. This is more striking when the first 24-hour urine percentage excretion of total radioactivity is related to the creatinine clearance (Table III, Fig. 2). In comparison with normal subjects there is, in the presence of impaired renal function, an increase in faecal excretion.

TABLE III-Creatinine Clearance and 24-hour Urinary Radioactivity Excretion \begin{tabular}{l|l|l} 
Case No. & Creatinine Clearance (ml/min) & $\% \mathrm{C}_{14}$ Dose Excreted in Urine
\end{tabular}

\begin{tabular}{lll|}
$\mathbf{1}$ & $\cdots$ & $\cdots$ \\
$\mathbf{2}$ & $\cdots$ & $\cdots$ \\
$\mathbf{3}$ & $\cdots$ & $\cdots$ \\
$\mathbf{5}$ & $\cdots$ & $\cdots$ \\
$\mathbf{6}$ & $\cdots$ & $\cdots$ \\
$\mathbf{7}$ & $\cdots$ & $\cdots$ \\
$\mathbf{8}$ & $\cdots$ & $\cdots$
\end{tabular}
Intravenous Administration

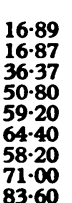

\begin{tabular}{|c|c|c|c|}
\hline & & Oral & \\
\hline $\begin{array}{rr}10 & \cdots \\
11 & \cdots \\
12 & \cdots \\
3(a) & \\
3(b) & . \\
13 & \cdots \\
14 & \cdots\end{array}$ & $\begin{array}{l}\because \\
\because \\
\because \\
\because \\
\cdots\end{array}$ & $\begin{array}{r}2.0 \\
2.6 \\
3.6 \\
5.0 \\
100.0 \\
9.0 \\
16.0\end{array}$ & $\begin{array}{r}4.37 \\
6.15 \\
7.73 \\
19.04 \\
75.76 \\
34.48 \\
61.08\end{array}$ \\
\hline
\end{tabular}

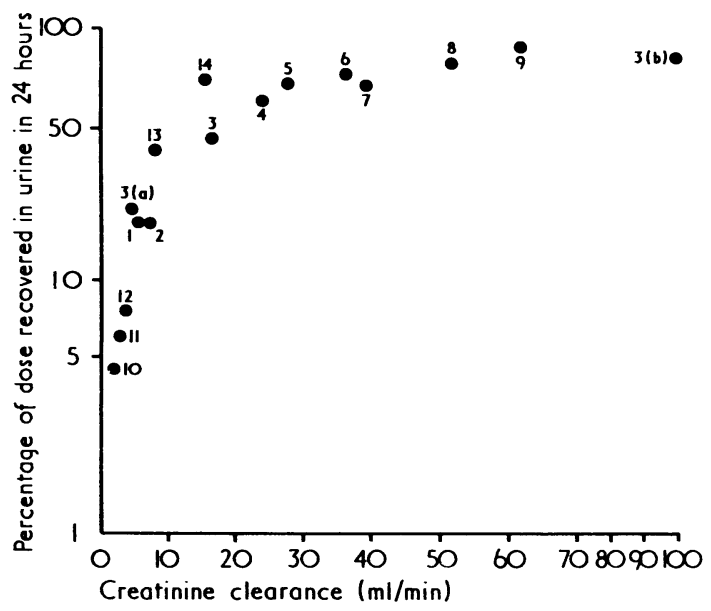

FIG. 2-Creatinine clearance and 24-hour urinary radioactivity excretion.
After oral administration in normal renal function peak levels of propranolol are found in the blood at about one hour. In patients with impaired renal function peak levels were reached at two to four hours. The peak levels of 4-hydroxypropranolol occurred at a similar time, with a secondary peak at six hours.

In those patients where the slopes of propranolol concentration in the serum during the six hours after administration allowed the half-life to be calculated, this was shorter than in subjects with normal function. In Fig. 3 the half-life of propranolol is plotted against creatinine clearance in those receiving the dose intravenously. There is clearly a direct relation.

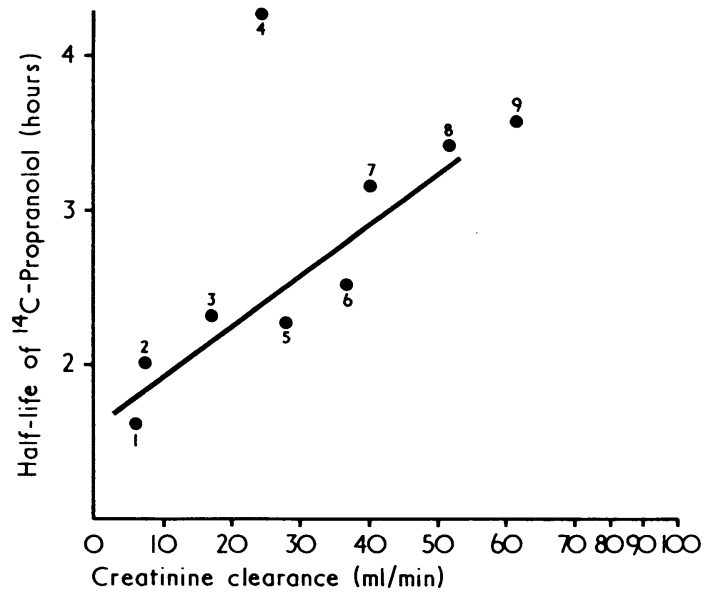

FIG. 3-Half-life of ${ }^{14} \mathrm{C}$-propranolol and creatinine clearance in patients receiving dose intravenously.

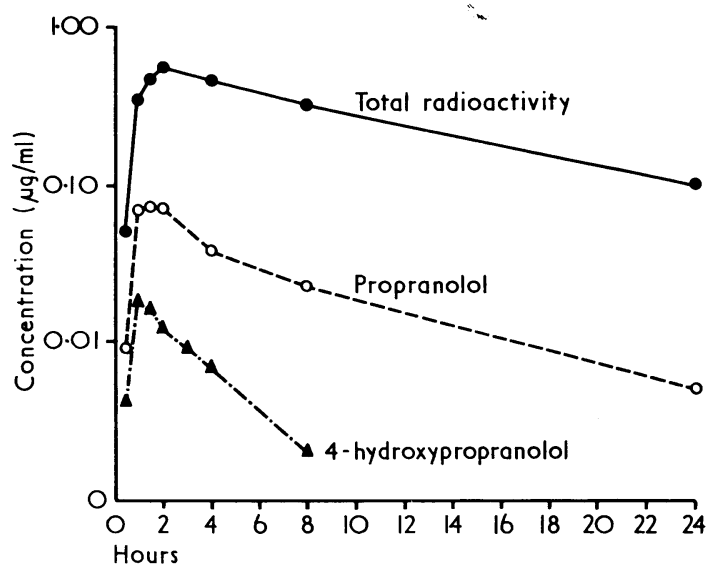

FIG. 4-Time-course relations between levels of propranolol and metabolites in blood of normal volunteers. 
In animals and man the uncharacterized metabolites of propranolol have a considerably longer half-life in the blood than the parent compound. A representation of the time-course relation between the levels of propranolol and these metabolites in blood of normal volunteers is shown in Fig. 4. With renal impairment the level of such metabolites found in the serum is up to three times higher than that seen in normal subjects. They are also more slowly cleared from the blood as seen by an increase in their half-life (Fig. 5). This is demonstrated only after oral administration when the total radioactivity in the blood was measured at 24 hours. Following intravenous dosage measurements were made only up to six hours after administration.

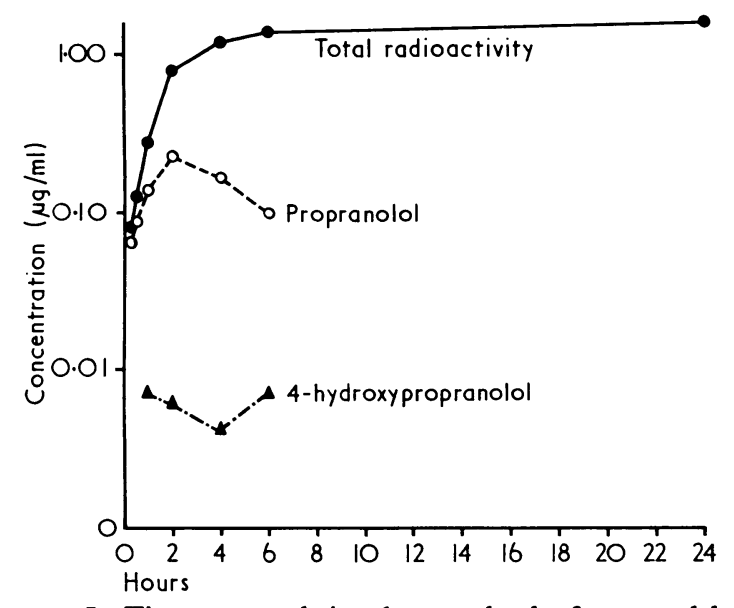

FIG. 5-Time-course relations between levels of propranolol and metabolites in patients with renal impairment.

\section{Discussion}

In the presence of renal failure there is a suggestion of delay in absorption of propranolol after an oral dose. There is no delay in the conversion of propranolol to the 4-hydroxymetabolite, nor in the formation of the acid labile conjugates of propranolol and 4-hydroxypropranolol. From observations after intravenous administration of propranolol it is seen that the half-life of both propranolol and the 4-hydroxymetabolite are shorter in the presence of renal functional impairment. There is no current explanation for this phenomenon, particularly as neither of these compounds is excreted to any extent in the urine either in the presence of normal or abnormal renal function.
By using ${ }^{14} \mathrm{C}$ labelling in the ring of the propranolol molecule, it has been possible to observe the handling of the total metabolites of the propranolol. After the disappearance of detectable propranolol and the 4-hydroxy compound the remaining radioactivity is thought to represent their conjugates; the urinary excretion of these compounds is directly related to renal function. The total plasma concentrations of metabolites after a single dose in renal impairment may reach three times that seen in the presence of normal renal function. There is, at present, no convincing evidence that the conjugates have a beta-blocking action. Nevertheless, it might be possible that the conjugates release either propranolol or 4-hydroxypropranolol in sufficient quantities to have a pharmacological effect. Further clinical observations will be necessary to establish whether a dosage regimen in the presence of renal failure will have to take this into account. There are no recognizable side effects due to the accumulation of the conjugates which may occur in such patients.

Higher faecal excretion was observed in the presence of renal failure. This compensatory mechanism is probably of importance in preventing undue accumulation of the conjugate.

In summary, the handling of propranolol in the presence of renal failure is not so altered as to suggest that an alteration in dosage is required from that used in the presence of normal renal function. However, careful long-term studies with continued propranolol dosage for the treatment of hypertension in the presence of renal failure are essential in order to establish this.

We wish to express our thanks for the expert technical help of Mr. R. G. Cooper, Mrs. J. S. Sidall, and Mrs. S. Gillott (I.C.I. Pharmaceuticals Division). We also wish to thank Mr. J. Burns (I.C.I. Pharmaceuticals Division) for the synthesis of radiolabelled propranolol and Mr. David Chew, S.R.N. (St. Philip's Hospital), for organizing the collection of samples.

\section{References}

Foulkes, D. M. (1970). Fournal of Pharmacology and Experimental Thera-

peutics, 172, 115 .
Hayes, A., and Cooper, R. G. (1971). Journal of Pharmacology and Experimental Therapeutics, 176, 302.

Kalberer, F., and Rutschmann, J. (1961). Helvetica Chimica Acta, 44, 1956. Paterson, J. W., Conolly, M. E., Dollery, C. T., Hayes, A., and Cooper,
R. G. (1970). Pharmacologia Clinica, 2, 127.

Prichard, B. N. C., and Gillam, P. M. S. (1969). British Medical fournal, $1,7$.

Zacharias, F. J., and Cowen, K. J. (1970). British Medical fournal, 1, 471.
$(29 \%)$ developed calf vein thrombosis as detected by the radioactive fibrinogen technique. None of the 24 heparinized patients had any evidence of venous thrombosis. This difference is significant at the $1 \%$ level.

\section{Introduction}

The M.R.C. (1969) trial of anticoagulant therapy for myocardial infarction showed that its only apparent significant effect was to reduce the incidence of thromboembolism. However, in that trial the diagnosis of deep vein thrombosis was made clinically, and it is now known that this can be misleading (Lambie et al., 